\title{
Implementing Reinforcement-Based Treatment (RBT) for Substance Use Disorders within child protective service systems in Europe
}

Child Protective Service Systems in Europe Cindy M. Schaeffer ${ }^{1}$, Cynthia C. Swenson ${ }^{1}$, Joanne E. Penman ${ }^{2}$, L. Michelle Tuten ${ }^{3}$.

${ }^{1}$ Department of Psychiatry and Behavioral Sciences, Medical University of South Carolina, ${ }^{2}$ Multisystemic Therapy Services, Inc., ${ }^{3}$ Department of Psychiatry, Johns Hopkins University.

Correspondence: email: schaeffc@musc.edu

\begin{abstract}
Parental substance misuse is a major concern internationally among child protective service systems charged with protecting children from maltreatment. Research in western countries indicates that substance misuse is a contributing factor in the vast majority of maltreatment cases that require child removal from the home. Unfortunately, parents involved in child protective services rarely access or complete treatment for substance misuse. A new approach to addressing the complex interrelated problems experienced by families in which child maltreatment has occurred known as Multisystemic Therapy for Child Abuse and Neglect (MST-CAN), is being implemented in numerous sites in the US and Europe. This article describes the provision of Reinforcement-Based Treatment (RBT), an intensive behavioural intervention for substance misuse developed in the US by MST-CAN service providers in Europe. Several challenges encountered in delivering RBT within the European context including balancing abstinence-only and harm reduction perspectives, making drug testing feasible, and implementing vocational interventions are discussed as well as how each challenge was managed. The authors conclude that the implementation of RBT in Europe with a child protective service system population has been successful and encourage further adoption of the model across different European contexts.
\end{abstract}

Keywords: Substance use disorders, Child protective service, Child abuse

Child Protective Service (CPS) systems are local government-run entities (e.g. city, county, province, borough) designed to protect children and adolescents from maltreatment. In most western countries CPS systems are situated within a larger umbrella of welfare services for individual adults (e.g. disability subsidies), children (e.g. medical insurance for children from low income families), and families (e.g. food stamps, housing assistance). CPS divisions work closely with the broader welfare system to provide a range of needed services to families in which child maltreatment is suspected or substantiated, including monitoring parent behaviour and referring families to mental health or substance 
abuse treatment. In more severe cases CPS may temporarily or permanently remove children from parental care, arrange for and monitor the success of foster care placements, and arrange for permanent child adoption.

Research in the US and UK CPS systems suggest that caregiver substance abuse is present in 50 - 70\% of all substantiated child maltreatment cases and in 60 $80 \%$ of cases that involve the removal of children from their homes. ${ }^{1-4}$ Internationally, cases involving parental substance abuse are among the most difficult for CPS systems to address. ${ }^{5}$ Relative to other child maltreatment cases, children of parents who abuse substances are more likely to experience re-abuse by the parent ${ }^{6-7}$ and in out-of home placement in foster care. ${ }^{8}$ Once removed, children of substance-abusing parents spend more time in out-ofhome placements ${ }^{9-10}$ and are more likely to experience a termination of parental rights9 than youth who are removed for other reasons. Out-of-home placements poses their own risks to children, including attachment problems, mental health difficulties, and school failure. ${ }^{11-12}$ Given the potentially devastating effects of co-occurring substance abuse and child maltreatment, it is essential that adults within the CPS system receive effective substance abuse treatment.

Unfortunately, such parents have difficulty accessing and utilising substance abuse services. A national survey of public child welfare agencies in the US indicated that only $31 \%$ of parents in their system who needed substance abuse treatment in fact received any substance abuse services. ${ }^{13}$ In the UK, surveys with child care social workers indicate parents rarely link to substance misuse specialists when referred, due largely to parental denial of substance problems. ${ }^{2,14-15}$ Parents in the CPS system who do access substance misuse services rarely complete them. Whereas adult substance abuse treatment completion rates in the US general population are $55 \%$ - 65\%16, only $20 \%$ of child welfare parents receive a full course of treatment. ${ }^{17}$ Poor completion rates are likely due to several factors, including the competing demands of other child welfare mandates (e.g. to attend court, parenting classes, and family therapy sessions) and structural barriers inherent in many treatment settings (e.g. lack of child care to attend sessions). Numerous international researchers and advocacy groups have called for better access to substance abuse treatment for CPS populations and better coordination between treatment and child

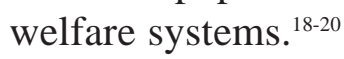

In this article, we describe how an empirically-supported behavioural substance abuse intervention known as Reinforcement-Based Treatment ${ }^{21}$ (RBT) is being delivered to parents served by CPS systems in the US and in Europe. RBT is delivered within the context of Multisystemic Therapy for Child Abuse and Neglect (MST-CAN), a comprehensive treatment model designed to address the 
multiple needs of families in the CPS system and to ameliorate the factors, including parental substance abuse, that pose a risk for re-abuse.

\section{Multisystemic Therapy for Child Abuse and Neglect (MST-CAN)}

Multisystemic Therapy ${ }^{22}$ (MST) is the core model on which MST-CAN is based. MST has come to be recognised as a leading evidence-based intervention for highly complex, multi-need families. ${ }^{23-24}$ MST programmes serve juvenile offenders in 34 US states, 14 European countries, Canada, Australia, New Zealand and Chile. MST-CAN ${ }^{25}$ is an adaptation of the original MST model tailored to meet the needs of families involved in the CPS system due to child maltreatment. Currently, MST-CAN programmes exist (or are soon to be launched) at 10 sites in three US states, three sites in England, and one site each in Switzerland and the Netherlands.

\section{The MST-CAN Approach}

A full description of MST-CAN is provided by Swenson \& Schaeffer. ${ }^{26}$ Briefly, MST-CAN uses a home-based model of service delivery to overcome barriers to service access and promote generalisation of treatment gains. Services are provided at times convenient to the family, and clinicians share a round-theclock on call roster for after hour crises. Treatment is intensive, with families seen several times per week. Considerable attention is given to forging positive relationships among family members and CPS staff.

MST-CAN provides evidence-based interventions individualised to meet the family's clinical needs. All families develop a safety plan, based on a functional analysis of maltreatment incidents, ${ }^{27}$ that outlines what family members will do if they feel unsafe or if a parent misuses substances. All families also participate in a clarification process to help the parent accept responsibility for the maltreatment and apologise to the child. ${ }^{28}$ Other evidence-based family and mental health interventions, such as prolonged exposure therapy for parental PTSD symptoms are incorporated as warranted. ${ }^{29}$

\section{Empirical support for MST-CAN}

Two randomised clinical trials support the effectiveness of MST-CAN in serving families experiencing maltreatment. ${ }^{30-31}$ A recent quasi-experimental study ${ }^{32}$ examined outcomes for an MST-CAN team in the US serving exclusively CPS families in which a parent had an active substance use disorder. Maternal selfreport measures taken before and after treatment indicated significant reductions in alcohol and drug use. Relative to comparison group families over a follow-up period of 24 months, MST-CAN mothers were three times less likely to have another substantiated incident of maltreatment; and MST-CAN youth spent significantly fewer days in out-of-home placements. 


\section{Reinforcement-Based Treatment (RBT)}

RBT21 is an incentive-based programme that integrates elements from cognitive-behavioural treatments for substance dependence with the Motivational Interviewing ${ }^{33}$ approach. RBT was originally designed to be delivered in an outpatient or intensive outpatient (i.e. day treatment) setting. A modified version of RBT designed for home-based delivery has been successfully implemented internationally within MST-CAN.

\section{The RBT approach}

RBT incorporates techniques from the community reinforcement plus vouchers ${ }^{34}$ and relapse prevention ${ }^{35}$ models, both of which have been studied extensively (for reviews see). ${ }^{36-37}$ RBT views substance abuse as a learned behaviour that is maintained by the reinforcement people receive for using drugs. Understanding why drug use 'works' for each individual (i.e. a functional assessment) therefore, is a key part of treatment planning. The therapist's main task is to help the client identify alternative ways to get the functions currently served by drug use (e.g. to have fun, to avoid mental health symptoms) met in other, more positive ways, and to incorporate new, reinforcing behaviours into the daily routine.

RBT treatment components include: short-term detoxification (5-7 days) when necessary (i.e. opiates or alcohol) to address physical dependency; feedback as a motivational technique; day-planning to avoid unstructured time; and contracts for specific behaviours (e.g. agreeing to avoid drug-using peers). Clinicians also use visually-appealing graphs highlighting days of abstinence, job goal attainment, recreational activities, and other important activities to help clients make links between their engagement in new activities and sobriety. Clients receive reinforcement (e.g. monetary vouchers, certificates) provided contingent on having negative drug testing results and on engaging in abstinence-supporting behaviours. Therapists use non-confrontational techniques and incorporate family members in treatment to support abstinence.

\section{Empirical support for RBT}

Three randomised clinical trials with heroin-dependent adults exiting detoxification facilities establish the efficacy of RBT as delivered in an outpatient treatment setting. ${ }^{38-40}$ These studies have demonstrated superior abstinence rates for clients receiving RBT for as long as six months following treatment. As noted, there also is preliminary evidence for the effectiveness of a home-based version of RBT delivered within MST-CAN. ${ }^{32}$

\section{RBT in the European context: implementation challenges and solutions}

To date, dissemination of RBT to Europe has occurred only within the context 
of the MST-CAN model, which is contracted to serve families involved in CPS. Delivered in this context, RBT is relatively buffered from many issues facing the broader substance misuse service system in Europe, such as long waiting lists for services or poor client-show rates. ${ }^{41}$ Nevertheless, differences between the US and European policies and cultural norms have presented some challenges for implementing RBT in Europe.

\section{An abstinence-based approach in a harm reduction-oriented system}

In the US, substance abuse treatment is dominated by abstinence-only approaches in which the client's full avoidance of all drugs is the goal. The abstinence-only approach has been criticised as being overly rigid and unrealistic thereby alienating clients who could benefit from interventions to help reduce or change aspects of drug use that create problems in functioning (e.g. drinking while driving or working). ${ }^{42}$ Harm reduction psychotherapy focuses on helping clients who are unwilling or unable to stop drug use to make lifestyle changes that reduce harm done to themselves, to their families, and to society that stems from use. ${ }^{43}$ Harm reduction approaches are prominent in Europe, particularly in the UK and the Netherlands. ${ }^{44}$

RBT has long-term abstinence as its goal and as such would seemingly be in conflict with prevailing professional norms in Europe. Fortunately, few clashes have actually occurred in practice, for several reasons. First, a harm reduction approach is less tenable when the safety of children is involved. An approach to substance misuse treatment that is overly tolerant of continued parental use runs the risk that children will have to be removed from the parents' care, which is the main outcome CPS is trying to prevent. Because MST-CAN is an intensive and relatively expensive treatment, CPS tends to refer only the most severe substance misuse cases, many involving multiple previous maltreatment incidents, for whom an abstinence-only approach is more warranted.

A second reason is that MST-CAN teams deliver RBT interventions relatively independent from the broader substance misuse service system. An exception is when parents are referred for supplemental interventions such as medical detoxification or buprenorphine treatment. In these cases the MST-CAN therapist coordinates closely with the service provider, which is greatly facilitated by the therapist's ability to work wherever necessary on behalf of the client (e.g. the client's home, a medical appointment, etc.). Meeting at times and locations convenient to the outside service provider does much to alleviate differences in theoretical orientation. Generally outside providers are very positive about MST-CAN and appreciate being part of a team approach.

Another effective strategy has been to include outside service providers in initial 
MST-CAN training sessions. Doing so promotes trust between the different providers and allows for discussion of potential issues. Invariably, in these settings we find a high degree of overlap in treatment philosophy and technique. For example, most service providers with a harm reduction perspective have worked with clients mandated to treatment (e.g. by probation) with the expectation that they achieve abstinence. In our experience, most service providers agree with the view that harm reduction encompasses a wide continuum of change options that includes abstinence. ${ }^{44}$

Similarly, the RBT approach incorporates principles from harm reduction, including an emphasis on client choice, validation of incremental changes, and an accepting, supporting stance towards relapses. Thus, a third reason why RBT has been favorably received within the European context is because it is in fact quite compatible with harm reduction. For example, the MST-CAN safety plan for parental relapse is a clear harm reduction tool because the therapist and the client plan ahead to determine which abstinent adult in the client's support network will care for the child in the event of a relapse. For many clients, a series of relapses and safety plan enactments simulates what the experience of losing custody of their children permanently would be like, and helps build motivation for full abstinence.

Surveys of substance misuse therapists in both the US and Europe indicate great openness to the use of both abstinence-oriented and harm reduction-oriented techniques in treatment, depending on client needs. ${ }^{45-46}$ Our experience delivering RBT in partnership with settings dominated by the harm reduction approach is consistent with this research.

\section{Differences in drug testing norms}

A central challenge we faced in implementing RBT in Europe was how to obtain valid and timely drug and alcohol test results. In RBT, results from objective drug and alcohol tests underlie many treatment components, including safety planning (and the 'lifting' of plans), providing positive reinforcement, and addressing relapses. In the US, urine drug tests are the gold standard and are administered routinely in treatment settings. Under monitored conditions, clients provide a urine sample in a small cup that they seal and give to the provider. Although test kits that require laboratory analysis are available, so-called 'instant' test cups are commonly used because they are inexpensive, sanitary, accurate, and easily administered.

When we began in England in 2009, there was great reluctance to ask non-medical providers to administer urine tests. At the time, other home-based treatment providers in England were using independent traveling nurse organisations for 
this task. Having travelling nurses test clients without the MST-CAN therapist present was inappropriate because it did not allow for the instant response to test results necessary for RBT to be effective (e.g. providing vouchers contingent upon abstinence). We also feared that clients might experience visits solely for the purpose of drug testing as punitive, which is contrary to RBT principles.

Hearing our concerns, local stakeholders proposed that MST-CAN therapists perform instant oral fluid testing, which, although more cumbersome to administer, could be done in the home and would also provide instant results. A cotton swab is rubbed against the client's cheek, smeared onto a cartridge, and fed into an apparatus, which then prints results for various drug categories. Unfortunately, a six-month trial period of this approach proved unsuccessful. A large portion (approximately 50\%) of samples taken was inconclusive, either due to problems in the methodology itself or mistakes in sample collection. Although lab-based analysis of oral samples is highly reliable, field-based instant testing needs further refinement. ${ }^{47}$

By this time, MST-CAN therapists had embraced RBT principles and were themselves requesting better procedures for understanding client drug status. Together, therapists, stakeholders, and model developers agreed to switch to an instant urine drug testing protocol similar to ones used in MST-CAN in the US. This approach has been found to be acceptable to all parties ever since, and was adopted by the other European sites.

\section{Promoting employment when clients receive strong social welfare benefits}

Another challenge in the implementation of RBT in Europe is motivating clients to pursue employment goals. Obtaining legal employment receives great emphasis within RBT because of the strong role work plays in supporting abstinence. Client employment has been found to be a strong predictor of abstinence following treatment in two literature reviews involving different substance misuse populations. . $^{4-49}$

In the US, unemployed adults receive few if any government financial benefits, making employment a necessity for most people. Although unemployed and low-income parents can receive subsidies for essential items such as food and housing, these benefits are rarely enough to live on. Accordingly, RBT clients in the US who are unemployed are generally more open to employment interventions that have strong potential to improve their standard of living. Even in light of current austerity measures, the social safety net for families in Europe is still far more generous than it is in the US. Generally, in Europe, a non-working single parent and her children can live adequately (though not comfortably) on government benefits alone. We have experienced significant 
difficulty in motivating clients to pursue job activities, and unfortunately in some cases, convincing staff of the value in exploring such goals with reluctant clients.

To address this challenge we have broadened our view of what a job is and have applied several cognitive and motivational techniques. For example, we emphasise to clients that many diverse activities can meet the functions that we want employment to provide i.e. free time filled so that boredom does not lead to drug use, meaningful social connections, recognition of competent performance, and a view of oneself as more than a drug user. MST-CAN therapists encourage clients to 'sample' (i.e. try one time only) various activities that have the potential to fulfill these functions, such as volunteering at their child's school. To dispel misperceptions that working results in less money than government subsidies, MST-CAN therapists outline what benefits the client will be able to retain if employed. In addition, therapists provide clients with objective information, from the scientific literature, about the benefits of working. Therapists also engage in decisional-balance exercises to help clients weigh for themselves the pros and cons of working versus remaining unemployed. Together, these techniques have improved our success in getting clients to consider employment or other productive behaviour pursuits.

\section{Legality and decriminalisation of Marijuana use}

A final relevant difference between the US and Europe context is in the legality of marijuana. Strictly illegal (with a few exceptions) in the US, marijuana use receives mild if any legal sanctions in the UK or Switzerland, and is completely decriminalised in the Netherlands. Although we expected much higher use of marijuana in our European sites than in the US, this has not proven to be the case. A client's drug of choice is far more dependent upon his or her learning history, exposure, and other personal factors than upon the legality of the drug in the client's country, since both legal and illegal drugs tend to be widely available.

Clients who misuse marijuana do tend to cite its legality as one rationale for persisting. The European client's perspective that he 'should' be able to use marijuana is analogous to the perspective of many clients in the US and Europe who misuse alcohol, which also is legal and socially acceptable. The RBT approach focuses on clients' individualised reasons to stop drug use and emphasises the personalised rewards they might receive for doing so. Warning of potential negative legal consequences for drug use is rarely helpful in motivating clients to try abstinence. One way the legality of the client's drug of choice may factor into RBT is in helping clients avoid cues for drug use, which tends to be more challenging for drugs such as alcohol that are highly available. For example, a 
client who is trying to avoid marijuana use in Amsterdam may need explicit coaching to avoid coffee houses, where olfactory and other cues are likely to induce cravings.

\section{Conclusions and future directions}

Despite its emphasis on abstinence, the delivery of RBT for substance misuse within a European context dominated by harm reduction approaches has been successful. The desire to protect children from the negative effects of parental substance misuse has been a unifying factor among stakeholders. The MI approach provided within RBT allows for the pursuit of both abstinence and harm reduction goals simultaneously, making it well-suited to the European context. It is our hope that RBT will experience further adoption within Europe in both home-based (i.e. within MST-CAN teams) and clinic-based (i.e. outpatient or inpatient) settings, and for clients both within and outside of the CPS system.

There is a need to evaluate the effectiveness of MST-CAN in Europe and to determine whether outcomes are similar to those obtained in the US. Currently, programme evaluations of MST-CAN are being conducted at each of the five European sites. We hope that should preliminary outcomes prove promising, more rigorous evaluations (e.g. randomised controlled trials) will be forthcoming.

\section{References}

1. Forrester D. Parental substance misuse and child protection in a British sample: A survey of children on the Child Protection Register in an inner London district office. Child Abuse Rev. 2000;9(4):235-46.

Doi: http://dx.doi.org/10.1002/1099-0852(200007/08)9:4<235::AIDCAR626>3.0.CO;2-4

2. Forrester D, Harwin J. Parental substance misuse and child care social work: findings from the first stage of a study of 100 families. Child Fam Soc Work. 2006;11(4):325-35.

Doi: http://dx.doi.org/10.1111/j.1365-2206.2006.00415.x

3. Osterling KL, Austin MJ. Substance abuse interventions for parents involved in the child welfare system: Evidence and implications. J Evid Based Soc Work. 2008;5:157-89.

http://dx.doi.org/10.1300/J394v05n01_07

PMid:19064448 
4. Young NK, Boles SM, Otero C. Parental substance use disorders and child maltreatment: Overlap, gaps, and opportunities. Child Maltreat. 2007;12:137-49.

Doi: http://dx.doi.org/10.1177/1077559507300322

PMid:17446567

5. Bor W, Stallman HM, Collerson E, Boyle C, Swenson CC, McDermott BM, et al. Value adding Australian child protection policy: The case for Multisystemic Therapy. Australas Psychiatry. Forthcoming 2013.

6. Brook J, McDonald T. The impact of parental substance abuse on the stability of family reunification from foster care. Child Youth Ser Rev. 2009;31:193-98.

Doi: http://dx.doi.org/10.1016/j.childyouth.2008.07.010

7. Ondersma SJ. Introduction to the first of two special sections on substance abuse and child maltreatment. Child Maltreat. 2007;12:3-6.

Doi: http://dx.doi.org/10.1177/1077559506296687

8. US Department of Health and Human Services, Administration for Children and Families. National study of protective, preventive, and reunification services delivered to children and their families. Washington, DC: US Government Printing Office. 1997.

9. Connell CM, Bergeron N, Katz KH, Saunders L,Tebes JK. Referral to child protective services: The influence of child, family, and case characteristics on risk status. Child Abuse Negl. 2007;31:573-88.

Doi: http://dx.doi.org/10.1016/j.chiabu.2006.12.004

PMid:17537504

10. Vanderploeg JJ, Connell CM, Caron C, Saunders L, Katz K H, Kraemer Tebes, J. The impact of parental alcohol or drug removals on foster care placement experiences: A matched comparison group study. Child Maltreat. 2007;12(2):125-36.

Doi: http://dx.doi.org/10.1177/1077559507299292

PMid:17446566

11. Harden BJ. Safety and stability for foster children: A developmental perspective. Future Child. 2004;14:31-47.

Doi: http://dx.doi.org/10.2307/1602753 
12. Stone S. Child maltreatment, out-of-home placement, and academic vulnerability: A fifteen-year review of evidence and future directions. Child Youth Ser Rev. 2007;29:139-61.

Doi: http://dx.doi.org/10.1016/j.childyouth.2006.05.001

13. Child Welfare League of America. Alcohol and other drug survey of state child welfare agencies, Washington, DC. 1997.

14. Hayden C. Parental substance misuse and child care social work: Research in a city social work department in England. Child Abuse Rev. 2004;13(1):18-30.

Doi: http://dx.doi.org/10.1002/car.828

15. Nagle A, Watson G. Parental substance misuse: An Islington perspective. Child Abuse Rev. 2008;17(6):444-53.

Doi: http://dx.doi.org/10.1002/car.1049

16. Dutra L, Stathopoulou G, Basden SL, Leyro TM, Powers MB, Otto MW. A meta-analytic review of psychosocial interventions for substance use disorders. Am J Psychiatry. 2008;165:179-87.

Doi: http://dx.doi.org/10.1176/appi.ajp.2007.06111851

PMid:18198270

17. Child Welfare Partnership. A study of families with children entering foster care in Oregon between 1992 and 1995, cohort III. Portland, Oregon: Portland State University. 1998.

18. Donohue B, Romero V, Hill HH. Treatment of co-occurring child maltreatment and substance abuse. Aggress Violent Beh. 2006;11:626-40.

Doi: http://dx.doi.org/10.1016/j.avb.2005.08.007

19. Forrester D, Copello A, Waissbein C, Pokhrel S. Evaluation of an intensive family preservation service for families affected by parental substance misuse. Child Abuse Rev. 2008; 17(6):410-26.

Doi: http://dx.doi.org/10.1002/car.1048

20. Taylor A, Kroll B. Working with Parental Substance Misuse: Dilemmas for Practice. Brit J Soc Work. 2004;34(8):1115-32.

Doi: http://dx.doi.org/10.1093/bjsw/bch132 
21. Tuten LM, Jones HE, Schaeffer CM, Stitzer ML. Reinforcement-based treatment for substance use disorders: A comprehensive behavioral approach. Washington, DC: American Psychological Association. 2012 Doi: http://dx.doi.org/10.1037/13088-000

22. Henggeler SW, Schoenwald SK, Borduin CM, Rowland MD, Cunningham PB. Multisystemic therapy for antisocial behavior in children and adolescents. 2nd ed. New York: Guilford Press; 2009.

23. Elliott DS. Blueprints for violence prevention. Series ed. University of Colorado, Center for the Study and Prevention of Violence. Boulder, CO: Blueprints Publications; 1998.

24. U.S. Public Health Service. Youth violence: A report of the Surgeon General. Washington, DC: 2001.

25. Swenson CC, Penman JE, Henggeler SW, Rowland MD. Multisystemic Therapy for Child Abuse and Neglect Training Manual. Unpublished treatment manual. Charleston: Department of Psychiatry and Behavioral Sciences, Medical University of South Carolina: 2011.

26. Swenson CC, Schaeffer CM. Multisystemic Therapy for child abuse and neglect: A comprehensive family-based treatment. In: Urquiza AJ, editor. Evidence-based approaches for the treatment of maltreated children. New York: Springer; Forthcoming 2013.

27. Kolko DJ, Swenson CC. Assessing and treating physically abused children and their families: A cognitive-behavioral approach. Thousand Oaks, CA: Sage; 2002.

28. Lipovsky JA, Swenson CC, Ralston ME, Saunders BE. (1998). The abuse clarification process in the treatment of intrafamilial child abuse. Child Abuse Negl.1998:22;729-41.

Doi: http://dx.doi.org/10.1016/S0145-2134(98)00051-9

29. Foa EB, Rothbaum BO. Treating the trauma of rape: Cognitive behavioral therapy for PTSD. New York: Guilford Press; 1998.

30. Brunk MA, Henggeler SW, Whelan JP. Comparison of multisystemic therapy and parent training in the brief treatment of child abuse and neglect. J Consult Clin Psychol. 1987;55(2):171-8.

Doi: http://dx.doi.org/10.1037/0022-006X.55.2.171

PMid:3571669 
31. Swenson CC, Schaeffer CM, Henggeler SW, Faldowski R, Mayhew AM. Multisystemic therapy for child abuse and neglect: A randomized effectiveness trial. J Fam Psychol. 2010;24:497-507.

Doi: http://dx.doi.org/10.1037/a0020324

PMid:20731496 PMCid:PMC2928578

32. Schaeffer CM, Swenson CC, Tuerk EH, Henggeler SW. Comprehensive treatment for co-occurring child maltreatment and parental substance abuse: Outcomes from a 24-month pilot study of the MST-Building Stronger Families program. Child Abuse Negl. 2013. Available online: http://www.sciencedirect.com/science/article/pii/S0145213413001129

33. Miller WR, Rollnick S. Motivational interviewing: Preparing people for change 2nd ed. New York: Guilford; 2002.

34. Budney AJ, Higgins ST. A community reinforcement plus vouchers approach: Treating cocaine addiction. U S Department of Health and Human Services, National Institutes of Health, National Institute on Drug Abuse. Rockville, Maryland; 1998.

35. Marlatt GA, Gordon JR. Relapse prevention: Maintenance strategies in the treatment of addictive behaviors. New York: Guilford Press; 1985.

PMid:3998247

36. Lussier JP, Heil SH, Mongeon JA, Badger GJ, Higgins ST. A metaanalysis of voucher-based reinforcement therapy for substance use disorders. J Addict. 2006;101:192-203.

Doi: http://dx.doi.org/10.1111/j.1360-0443.2006.01311.x

PMid:16445548

37. Pearson FS, Prendergast ML, Podus D, Vazan P, Greenwell L, Hamilton Z. Meta-analyses of seven of the National Institute on Drug Abuse's principles of drug addiction treatment. J Subst Abuse Treat. 2011;43:1-11.

http://dx.doi.org/10.1016/j.jsat.2011.10.005

PMid:22119178 PMCid:PMC3290709 
38. Gruber K, Chutuape MA, Stitzer ML. Reinforcement-based intensive outpatient treatment for inner city opiate abusers: A short-term evaluation. Drug Alcohol Depend. 2000;57:211-23. http://dx.doi.org/10.1016/S0376-8716(99)00054-X

39. Jones HE, Wong CJ, Tuten M, Stitzer ML. Reinforcement-based therapy: 12-month evaluation of an outpatient drug-free treatment for heroin abusers. Drug Alcohol Depend.2005;79:119-28.

http://dx.doi.org/10.1016/j.drugalcdep.2005.01.006

PMid:16002021

40. Tuten M, Defulio A, Jones HE, Stitzer M. Abstinence-contingent recovery housing and reinforcement-based treatment following opioid detoxification. J Addition. 2012;107(5):973-82.

http://dx.doi.org/10.1111/j.1360-0443.2011.03750.x

PMid:22151478 PMCid:PMC3421907

41. Drummond C, Gual A, Goos C, Godfrey C, Deluca P, Von Der Goltz C, et al. (2011). Identifying the gap between need and intervention for alcohol use disorders in Europe. J Addict. 2011;106(1):31-6.

http://dx.doi.org/10.1111/j.1360-0443.2010.03335.x

PMid:21324019

42. International Harm Reduction Association. What is harm reduction? A position statement from the International Harm Reduction Association. 2010, May; Available from IHRA website: http://www.ihra.net/files/2010/08/10/Briefing_What_is_HR_English. pdf.

43. Tatarsky A, Kellogg S. Harm reduction psychotherapy. In: Marlatt GA, Larimer ME, editors. Harm reduction: Pragmatic strategies. 2nd ed. New York: Guilford Press; 2012;36-61.

44. Collins SE, Clifasefi SL, Logan DE, Samples LS, Somers JM, Marlatt GA. Current status, historical highlights, and basic principles of harm reduction. In: Marlatt GA, Larimer, ME, editors. Harm reduction: Pragmatic strategies. 2nd ed. New York: Guilford Press; 2012;3-35. 
45. Eversman M. Harm reduction practices in outpatient drug-free substance abuse settings. J Subst Use. 2012;17(2):150-62.

http://dx.doi.org/10.3109/14659891.2010.540295

46. Rosenberg H, Melville J. Controlled drinking and controlled drug use as outcome goals in British treatment services. Addict Res Theory. 2005;13(1):85-92.

http://dx.doi.org/10.1080/16066350412331314894

47. Dolan K, Rouen D, Kimber J. An overview of the use of urine, hair, sweat and saliva to detect drug use. Drug Alcohol Rev. 2004;23(2):213-17.

http://dx.doi.org/10.1080/09595230410001704208

PMid:15370028

48. Adamson SJ, Sellman JD, Frampton CMA. Patient predictors of alcohol treatment outcome: A systematic review. J Subst Abuse Treat. 2009;36:75-86.

http://dx.doi.org/10.1016/j.jsat.2008.05.007

PMid:18657940

49. Scherbaum N, Specka, M. Factors influencing the course of opiate addiction. Int J Meth Psych Res. 2008;17(1): S39-S44.

http://dx.doi.org/10.1002/mpr.244

PMid:18543361 